\title{
Dossiê Temático: África: memória e projeções de desenvolvimento - Apresentação
}

\section{Thematic Dossier: Africa: memory and development projections - introduction \\ Dossier temático: África: memoria y proyecciones de desarrollo - Presentación}

Rodrigo Corrêa Teixeira ${ }^{1}$

DOI: 10.5752/P.1809-6182.2019v16.n2.p2

A escrita contemporânea da Historia Global da África pode ser compreendida, no sentido restrito, a partir da História outrora triunfante da antiga metrópole. No sentido mais amplo, agora o único a ser usado, deve-se enquadrar a África na História das sociedades colonizadas ou na História das colonizaçôes (FERRO, 1996, 2004 e 2017).

A denominada "História Colonial", atualmente, envolta de um matiz pejorativo - desenvolveu-se ao mesmo tempo que os Impérios, que exprime uma ótica claramente "eurocêntrica". Os historiadores desse período tornaram-se, para os de hoje, mais fontes de referência, a ser desconstruída e ressignificada.

O objetivo principal consistia, ao mesmo tempo que se justificavam as conquistas, em estabelecer a filiação entre a tradução do grande comércio marítimo ocidental e a "valorização" imperial. O mais alto ponto dessa perspectiva foi atingido paralelamente ao processo de expansão colonial europeia - marcado pelo Primeiro Congresso Internacional de História Colonial, em Paris, em 1931 -, que res- saltava as tendências cronológica e temática, permeadas por julgamentos morais dessa abordagem (MORETTIN, 2014).

Os primeiros historiadores da colonização foram, portanto, viajantes, na maior parte das vezes administradores cuja intimidade com os "nativos" incitou a tornar precisos seus conhecimentos sem deixar de participar de um quadro social e político de que eram representantes e os instrumentos. A história colonial foi assim obra dos militares, dos funcionários, públicos, dos missionários, até mesmo dos agentes econômicos (exploradores, comerciantes, homens de negócios) da época; entre eles, ela contou com Georges Hardy (1953), o grão-mestre do ensino colonial da História, trabalhou no além-mar (expressão usual na França da época) como inspetor de Instrução Pública.

Quem constituiu a grande exceção ao espírito colonial hegemônico foi Charles André Julien (1994), militante do anticolonialismo de esquerda, nadando na contracorrente da maior parte de seus

\footnotetext{
1 Professor de Relaçôes Internacionais, Departamento de Relaçôes Internacionais da Pontifícia Universidade Católica de Minas Gerais (PUC-MG), Belo Horizonte, Brasil. ORCID: 0000-0002-9107-0498
} 
contemporâneos. Ele foi para a História Colonial do Magreb o que Jean Dresch (1979) foi para a geografia dos países árabes. Comprova-se, no caso pela forma anti-hegemônica, de que na época colonial não podia existir uma historia "neutra" da civilização: era-se a favor ou contra, nos escritos e na ação.

A História estava fundamentada nas colônias como sendo um "objeto de pesquisa" isolado e no postulado da documentação escrita. A História, como ainda afirma certos manuais escolares, começava, sem contestaçáo e sem interrogaçáa, com a escrita. No entanto, deve-se prestar uma atenção particular à “Etnologia Colonial", pois sua contribuição científica tornou-se patente, quando da Exposição Colonial de 1922, em Marselha, onde foram apresentadas coleçóes privadas de arte "negra”, não mais somente como objeto estético, mas com o propósito explícito de utilizá-los para reconstituir a história "primitiva" dos povos que representava (THOMAZ, 2002).

Como a História Colonial, também a Etnografia Colonial foi o domínio de homens conhecedores da regiáo, que ali deveriam permanecer por muito tempo - de maneira privilegiada: os funcionários coloniais. Mas estes, com frequência, náo estavam convencidos da superioridade - então explícita e implícita - do "homem branco"; foram seduzidos por povos que encaravam sem desprezo, conquistados pelas relaçóes que estes mantinham com o espaço e o tempo, pelo modo de vida que levavam, às vezes refinado, revelador de uma cultura milenar (como na Etiópia), pelas línguas que falavam e que tiveram liberdade para estudar e utilizar, pelas artes variadas, tais como a escultura e as danças. Eles dedicaram tempo a escutar e a transcrever, e suas obras, embora às vezes discutíveis no plano do rigor científico, ainda servem de referencia, notadamente entre os povos de cultura oral, aos quais anos de colonização fizeram, daí em diante, esquecer ou deformar suas tradiçóes; assim Samuel
Jonhson sobre a História Iorubá (1921) e Jean Gallais sobre o Sahel (2002).

A História dos povos colonizados emergiu sobretudo a partir das independências. $\mathrm{O}$ caso da história africana é exemplar senão caricatural, por motivos de uma característica das sociedades em causa - a de serem quase desprovidas de fronteiras escritas autóctones. A História da África tornou-se assim possível graças à conjunção de dois parâmetros que se produziram (será um acaso?) ao mesmo tempo: o fim dos regimes coloniais e o fim do primado incontestado das únicas fronteiras escritas (COQUERY-VIDROVICH; MONIOT, 1976).

A gênese da disciplina não transcorreu sem dificuldade. Os historiadores "clássicos" opuseram-se a admitir o gênero, por dois motivos: o primeiro devido à herança etnográfica - então desconhecida dos historiadores. O segundo atribuível à formação "não profissional" dos primeiros historiadores da colonização, cujos trabalhos por essa razão demonstravam às vezes mais boa vontade do que capacidade: é verdade que seus estudos documentados eram com frequência mais lineares e descritivos (numa palavra, "factuais") do que sintéticos e explicativos. Além disso, a incompreensão foi mantida pela preocupação que tiveram de se distinguir: conscientes como estavam de serem "marginalizados" por seus colegas, reagiram mediante a invençâo de uma nova disciplina, a "etno-história". Em seu tempo, foi uma ideia útil, mas não necessariamente justa, porque a necessidade de recorrer à totalidade das fontes disponíveis (escritas, mas também orais, arqueológicas etc.), prestando testemunho de vida do grupo, é hoje reconhecida como coisa própria do historiador, quem quer que seja, e seja qual for o domínio.

As sociedades não-ocidentais não devem ser consideradas nem isolada nem unicamente. Portanto, compreender que as sociedades africanas são como as outras, pensar seu cotidiano, apreender 
que sua especificidade é de ordem estritamente histórica. Há mais de um século os Estudos Africanos começaram a de organizar institucionalmente. Esse africanismo oficial não facilitou, exatamente, a compreensão do continente para além das representações predominante eurocêntricas, por maior que seja a massa considerável de conhecimentos que tenham sido reunidos (MUNDIMBE, 2013 e 2014). De maneira análoga, pode-se expressar a respeito dos males (SAID, 1995, 2001 e 2007) e dos benefícios do "Orientalismo" (IRWIN, 2006).

Na mesma ordem de ideias, uma contribuição específica dos historiadores e antropólogos marxistas foi, na década de 1970, a reflexão sobre os "modos-de-produção" pré-capitalistas; "asiático"? "africano"? (SURET-CANALE, 1958, 1964 e 1974) "tributário"? (AMIN, 1972) "da mesma linhagem" (REY, 1978) etc. - quer dizer, o estudo das estruturas sociais internas ligadas à organização da produção: análise, nas sociedades dominadas, das forças produtivas (sociedades rurais com baixo nível tecnológico, com renda fundiária inexistente, mas com circuito comercial desenvolvido, tanto em nível local como para as trocas distantes); sobretudo, análise das relaçôes sociais de produçấo: quem exerce o controle sobre as terras, o artesanato ou o grande comércio?; quais são as interaçôes entre domínio econômico e poder político? E, em consequência o que dizer sobre as modalidades da articulaçáo, da lavoura e da evoluçáo/desnaturaçáo do (ou dos) modo (s) de produção das sociedades dominadas pelo muno capitalista dominante, precisamente desde o início do encontro entre os dois, mediante "situação colonial" (BALANDIER, 2013)?

Um outro debate maior da História Colonial travou-se sobre o imperialismo - primeiro entre historiadores marxistas e não-marxistas (a favor ou contra um "imperialismo colonial" no sentido econômico do termo), depois entre os historiadores marxistas eles próprios, preocupados em corrigir e apurar uma interpretação demasiado redutora das análises leninistas revistas e corrigidas pela experiência stalinista. A polêmica permitiu por em termos novos a relação entre ideologia, política e economia, não apenas nas origens da conquista, mas ao longo do século XX (será possível distinguir o imperialismo da colonizaçáo? Houve lutas pelas independências ou recuo de um imperialismo europeu em crise? Que aproximaçôes e distanciamentos existem entre o imperialismo do início do século XX, a dominação sobre o Terceiro Mundo durante a Guerra Fria e a colonialidade sobre o Sul Global hoje?).

Herdado do precedente, um outro tema de encontro, mais precisamente entre historiadores e economistas, consiste na questão das origens, dos dados e da perspectiva do subdesenvolvimento, através da história da instituição e da periodização de um sistema ocidental de domínio/dependência desde a origem dos contatos até os nossos dias (SLENES, 1995; TOMICH, 2011; M'BOKOLO, 2009 e 2011) - ocasião de confrontar a tese da decolagem ou do arranco (take off) para o desenvolvimento econômico de Rostow (1978), àquele de um fenômeno histórico localizável do "intercâmbio desigual" entre "Centro" e "Periferia", e que resultou na expansão atual da "capitalismo periférico" e juntando-se, por isso mesmo, às preocupaçóes dos economistas do Desenvolvimento. Abriu-se aqui para uma ampla discussão sobre o fenômeno internacional, por exemplo, no pensamento latino-americano.

Cada vez mais hoje pode-se falar de uma vertente entre outras da ciência histórica em seu conjunto; são numerosas as pistas a descobrir, que permitem explicar profundas subversóes sociais internas oriundas do traumatismo colonial: transformaçôes socioeconômicas ligadas ao "esforço de guerra” de Primeira Guerra Mundial; mutaçóes que se cristalizaram por ocasião da grande depressão da 
década de 1930; subversóes estruturais iniciadas na virada da Segunda Guerra Mundial, anunciadoras, por sua vez, da descolonização e prelúdio à emergência do Terceiro Mundo "subdesenvolvido", a análise superou a mania "fatual" para privilegiar, mediante os mecanismos que progressivamente aceleram, desde o início do século XX, os processos interdependentes da ascensão da crise dos campesinatos, da Constituição de uma força de trabalho em via de proletarização e de urbanizaçáo, emergem também os temas de história do trabalho, da historia demográfica, climática e sanitária, da história cultural (aculturação, desculturação) e a do poder político, desde os sistemas de costumes pré-coloniais até o "conjunto administrativo de chefes "colonial e o Estado modernizado: em suma, a "História colonial" já desapareceu como tal.

A reflexão sobre as origens e a história da dependência, se situa no quadro interpretativo de Immanuel Wallerstein sobre a "Economia-Mundo Global" (1974, 1990, 1994, 2010 e 2017). A condição em que a África foi incorporada ao Sistema-Mundo Moderno, estruturalmente, numa posição da região periférica, permanecendo como tal até hoje. Contudo, o contexto recente de melhora dos indicadores econômicos e a crescente estabilidade política, atrelados aos interesses e projeçôes de outros países sobre a região, podem contribuir para avaliar eventuais instrumentos de ascensão e desenvolvimento. Num contexto de mudança sistêmica, surge a questão sobre em que medida a projeção chinesa pode contribuir para o efetivo desenvolvimento da África e qual papel essa regiáo desempenharia na ascensão da potência asiática um futuro centro na geopolítica global, ainda que uma recente desaceleração chinesa coloque desafios (LIMA, 2019).

Diante de um esgotamento de uma história colonial e mesmo de uma História do Terceiro Mundo, trabalha-se por uma História do Sul Glob- al, que tanto contemple entrelaçamentos inter-regionais, quanto as dinâmicas contraditórias do capitalismo global (HARVEY, 2016). A insistência de uma estrutura de colonialidade (MIGNOLO, 2003 e 2004) sobre a África coloca o desafio de um conhecimento e de uma práxis emancipatória. Nessa perspectiva, não podemos negar o papel primordial da África na escrita de uma geo-história do processo moderno de globalização, da teorização contemporânea nos campos da História das Relaçóes Internacionais, da Economia Política Internacional e da Geopolítica.

\section{Referencias}

AMIN, Samir. Underdevelopment and Dependence in Black Africa: Historical origin. Journal of Peace Research, v. 9, n. 2, 1972, p. 105-120.

BALANDIER, Georges. Sociologia das Brazzavilles Negras. Mangualde; Ramada: Ediçóes Pedago; Luanda: Ediçôes Mulemba, 2013.

COQUERY-VIDROVICH, C.; MONIOT, H. Africa negra de 1800 a nuestros dias. Barcelona: Editorial Labor, 1976.

DRESCH, Jean. Un géographe au déclin des Empires. Paris: Éditions La Découverte; Collection Hérodote, 1979.

FERRO, Marc (Org.). O livro negro do colonialismo. Rio de Janeiro: Ediouro, 2004.

FERRO, Marc. História das colonizaçóes: das conquistas às independências, séculos XIII a XX. São Paulo: Cia. das Letras, 1996.

FERRO, Marc. A colonizaçáo explicada a todos. São Paulo: Ed. Unesp, 2017.

GALLAIS, Jean. Alguns Aspectos do Espaço Vivido nas Civilizaçóes do Mundo Tropical. In: CORRÊA, Roberto Lobato; ROSENDAHL, Zeny. (Orgs.). Geografia Cultural: Um Século (3). Rio de Janeiro: Ed UERJ, 2002. p. 63-81.

HARDY, Georges. Histoire sociale de le colonization française. Paris: Larose, 1953.

HARVEY, David. 17 contradiçóes e o fim do capitalismo. São Paulo: Boitempo, 2016.

IRWIN, Robert. Pelo Amor ao Saber: Os Orientalistas e seus Inimigos. Rio de Janeiro: Editora Record, 2006.

JOHNSON, Samuel. The History of the Yorubas. London: Routledge and Kegan Paul, 1921.

JULIEN, Charles-André. Histoire de l'Afrique du Nord; Des origines à 1830. Payot: Paris, 1994.

LIMA, Marcos Costa. Impacts of Chinese economy and its 
global geopolitics: after the slowdown. Estudos Internacionais. Belo Horizonte, v. 7, n. 2, ago. 2019, p.21- 41.

M’BOKOLO, Elikia. África Negra: História e Civilizaçôes; tomo I (até o século XVIII). São Paulo, Salvador: Casa das Áfricas, EDUFBA, 2009.

M’BOKOLO, Elikia. África Negra: História e Civilizaçôes; tomo II (do século XIX aos nossos dias). São Paulo, Salvador: Casa das Áfricas, EDUFBA, 2011.

MIGNOLO, Walter D. Histórias Locais/Projetos Globais: Colonialidade, saberes subalternos e pensamento liminar. Belo Horizonte: Ed. UFMG, 2003.

MIGNOLO, Walter D. Os esplendores e as misérias da "ciência”: colonialidade, geopolítica do conhecimento e pluri-versalidade epistémica. In: SANTOS, Boaventura de Sousa (Org.). Conhecimento prudente para uma vida decente: 'Um discurso sobre as ciências’ revisitado. São Paulo: Cortez, 2004, p. 667-709.

MORETTIN, Eduardo Victorio. Colonizar é civilizar: o cinema e a Exposição Colonial Internacional (Vincennes, 1931). História. Questóes e Debates, v. 61, p. 233-249, 2014.

MUDIMBE, V. Yves. A Ideia de África. Mangualde; Ramada: Ediçôes Pedago; Luanda: Ediçōes Mulemba, 2014.

MUDIMBE, V. Yves. A Invençáo da África: Gnose, filosofia e a ordem do conhecimento. Mangualde; Ramada: Ediçốes Pedago; Luanda: Ediçôes Mulemba, 2013.

REY, Pierre-Philippe. O modo de produção de linhagem. In: CARVALHO, Edgar de Assis (org.). Antropologia econômica, São Paulo, Ed. Ciências Humanas, 1978, p. 137-96.

ROSTOW, W. W. Etapas do Desenvolvimento Econômico. Rio de Janeiro: Zahar Editores, 1978.

SAID, Edward W. Cultura e imperialismo. São Paulo: Companhia das Letras, 1995.

SAID, Edward W. O orientalismo reconsiderado: Reflexôes sobre o exílio e outros ensaios. Sáo Paulo: Companhia das Letras, 2001.
SAID, Edward W. Orientalismo: O oriente como invenção do Ocidente. São Paulo, Companhia das Letras, 2007.

SLENES, Robert W. "Malungu, Ngoma vem!" África encoberta e descoberta no Brasil. Cadernos do Museu da Escravatura. Luanda: Ministério da Cultura, 1995, p. 48-67.

SURET-CANALE, Jean. Afrique noire occidentale et centrale: t. 2. L'ère coloniale, 1900-1940. Paris, Éditions sociales, 1964.

SURET-CANALE, Jean. Afrique noire occidentale et centrale: t. 1. Géographie, civilisations, histoire. Paris, Éditions sociales, 1958.

SURET-CANALE, Jean. As sociedades tradicionais na África Tropical e o conceito de Modo-de-Produção Asiático. In: CERM. O Modo de produçáo Asiático. Lisboa: Seara Nova, 1974, p. 111-146.

THOMAZ, Omar. Ecos do Atlântico Sul: representaçôes sobre o terceiro império português. Rio de Janeiro: Editora da UFRJ/FAPESP, 2002.

TOMICH, Dale W.: Pelo prisma da escravidáo: Trabalho, capital e economia mundial. Sáo Paulo: EdUSP, 2011.

WALLERSTEIN, Immanuel. A África e a economia-mundo. In: AJAYI, Ade (Org.) História Geral da África, vol. VI (África do século XIX à década de 1880). Brasília: UNESCO, 2010, p. 27- 46.

WALLERSTEIN, Immanuel. A política dos Estados Unidos em relação à África. Lisboa: Iniciativas Editoriais, 1974.

WALLERSTEIN, Immanuel. O sistema mundial moderno, vol. I: A agricultura capitalista e as origens da economia-mundo europeia no século XVI. Porto: Ed. Afrontamento, 1990.

WALLERSTEIN, Immanuel. O sistema mundial moderno, vol. II: O mercantilismo e a consolidação da economia-mundo europeia 1600-1750, Porto: Ed. Afrontamento, 1994.

WALLERSTEIN, Immanuel. The World-System and Africa. New York: Diasporic Africa Press, 2017. 